\title{
Література:
}

1. CAP Laboratory Accreditation Checklists. College of American Pathologists (CAP).325 Waukegan Road, Northfield, IL 60093-2750 http://www.cap.org

2. CLSI C28-A3 Defining, Establishing, and Verifying Reference Intervals in the Clinical Laboratory - Third Edition; Approved Guideline, CLSI: Wayne, PA., 2008

3. CLSI EP15-A2 User verification of performance for precision and trueness - Second Edition; Approved Guideline, CLSI: Wayne, PA., 2005

4. Development of national laboratory policies. Best practices document and facilitators' guide. WHO Regional Office for Europe, 2017. - $87 \mathrm{p}$

5. htpp://www.cms/gov/clia/

6. James $\mathrm{O}$. Westgard, $\mathrm{PhD}$. Internal quality control: planning and implementation strategies. http://www.westgard.com/downloads/cat_view/ 52-papers

DOI https://doi.org/10.30525/978-9934-26-113-8-15

\section{ОПРЕДЕЛЕНИЕ И КОРРЕГИРОВАНИЕ ПСИХОЭМОЦИОНАЛЬНОГО НАПРЯЖЕНИЯ ПРИ ИШЕМИЧЕСКОЙ БОЛЕЗНИ СЕРДЦА, ГИПЕРТОНИЧЕСКОЙ БОЛЕЗНИ И СОМАТОФОРМНЫХ РАССТРОЙСТВАХ}

\author{
Сисецкий А. П. \\ кандидат медицинских наук, \\ ассистент кафедры Внутренней медицины № 3 \\ Национальный медицинский университет имени А. А. Богомольиа \\ г. Киев, Украина
}

Сердечно-сосудистые заболевания, в частности ишемическая болезнь сердца (ИБС) и гипертоническая болезнь (ГБ) характеризуются высоким уровнем неконтролированого психоэмоционального напряжения, особенно в сочета-нии с тревожно-депрессивными расстройствами. Этому способствует и не-адекватная психологическая реактивность таких пациентов. Для визуализа-ции психоэмоциональных расстройств при ИБС, ГБ, соматоформных расст-ройствах (СФР) и контроля процесса их коррекции разработаны «Тестовая самоидентификационная система» (ТЕCС) и методика «Самооценки уровня психоэмоционального напряжения» (СУПН). 
Материал и методы. 50 пациентам - мужчины $44,8 \pm 1,2$ лет с стабильной стенокардией напряжения II-III ФК, гипертонической болезнью II ст. и тре-вожно-депрессивными расстройствами, которые получали традиционное лечение ( $\beta$-адреноблокаторы, нитропрепараты, блокаторы кальциевых кана-лов, транквилизаторы), в течение 10 дней проводились ландшафтная образ-ная кинезиотерапия (ЛОК) и голографическое моделирование (ГM). Иссле-довались психоэмоциональное напряжение и психологическая реактивность пациентов, ишемическая активность, кардиогемодинамика. Верификация проводилась коронаровентрикулографией, суточным мониторингом ЭКГ и артериального давления , ВЭМ, ЕхоКГ, « ТЕСС»,» СУПН «.

Для определения психоэмоционального состояния пациента начальное тестирование проводилось с использованием базисной геометрической фигуры, восприятие которой отличается высоким уровнем нейрофизиологи-ческой активности, - квадрата. " $\boldsymbol{T E C C}$ состоит из сгрупированных в два блока квадратов, каждый из которых содержит горизонтальный и вертикаль-ный ряды. Горизонтальный ряд состоит из шести базисних квадратов, верти-кальный - из семи, каждый из которых включает большие внешние и мень-шие внутренние разноструктурированые квадраты полярных цветов - чёрно-го и белого.

\section{Тестовая самоидентификационная система}

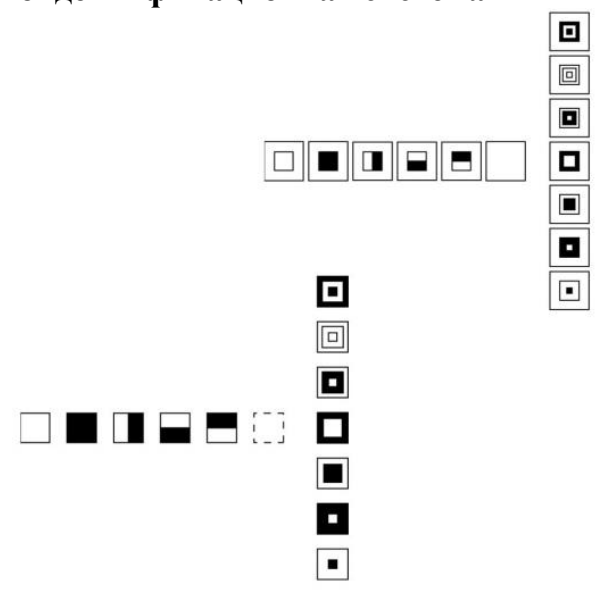

При тестировании пациент вибирает в горизонтальном и вертикальном рядах вначале первого, а затем второго блоков квадрат, который наиболее импони-рует, и негативно воспринимающийся квадрат. При этом вначале выбирается наиболее импонируемый квадрат 
из первого блока, начиная с горизонталь-ного ряда, и квадрат, который наименее понравился, затем эта же операция повторяется с другим блоком. Выбор квадрата с белым центром оценивается как синхронизированное, позитивное, гармоническое восприятие себя. Выбор квадрата $з$ чёрним центром - негативное, несинхронизированное, негар-моничное восприятие. Выбор квадрата с чёрно-белым центром неоднознач-ное неопределённое самовосприятие. С целью контроля изменения психо-эмоционального состояния в динамике тестирование проводится дважды.

СУПН включает шесть вертикальных шкал, которые отвечают определённым негативным эмоциональным состояниям - тревожность, страх смерти, агрессивность, отчаяние, одиночество, суицидность и депрессия - и скомбинированы из десяти одинаковых квадратных контуров, нижний из которых соответствует минимальному уровню психоэмоционального напряжения (один бал за десятибальной шкалой), а верхний - максимальному (десять балов).

\section{CAМООЦЕНКА УРОВНЯ ПСИХОЭМОЦИОНАЛЬНОГО НАПРЯЖЕНИЯ}
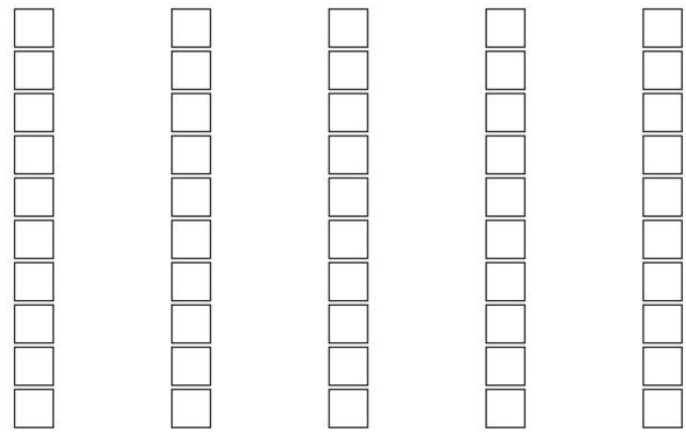

Тревожность

\section{Страх смерти}

Агрессивность

Отчаяние

Одиночество
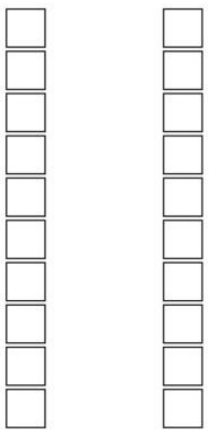

Суишидность Депрессия

ЛОК. Пациент осуществляет ходьбу и одновременно мысленно фиксирует положительные образы природы, которые впоследствии воспроизводит в домашних условиях. Затем - комплекс индивидуально подобраных стати-ческих и динамических релаксационных и дыхательных упражнений, кото-рые он модифицирует наиболее благоприятным для себя способом. При этом упражнения выполняются с визуализацией во внутреннем поле зрения пред-варительно отобранных 
позитивных образов природы с учётом кардиогемо-динамических параметров.

ГM. Пациент визуализирует интегративный образ (голограмму) своего внутреннего состояния с использованием всех груп анализаторов - зритель-ного, слухового, вкусового, нюхового, тактильного и проприоцептивного - с дальнейшим кинестетическим закреплением, результаты которого учитыва-ют при разработке рекомендаций по оптимальной физической и психической активности пациента. На основании конкретной шкалы психоэмоционально-го состояния с конкретным индивидуальным инструментом - образом собст-венного состояния - происходит реальное структурирование внутреннего психологического пространства. При этом достигается максимально адек-ватная самооценка в заболевании - непременного условия эффективных тера-пии и реабилитации. Для метода характерна глубокая личностная графиче-ская и кинестетическая самоидентификация при минимальном риске негатив-ного эффекта психологического вмешательства. Психологическая стабиль-ность достигается вследствие кинестетического (синхронизированного с дыхательными движениями) и графического (свободный ассоциативный рисунок, коррегирующий текст) отражения неосознанных психотравмируую-щих факторов с целью создания адекватного позитивного образа собственно-го состояния .

Результати. С учётом кардиогемодинамических показателей определены четыре типа реактивности больных с ИБС, ГБ и СФР: I. Адекватный. II. Ги-перактивный платовый: 1) позитивный; 2) негативный.

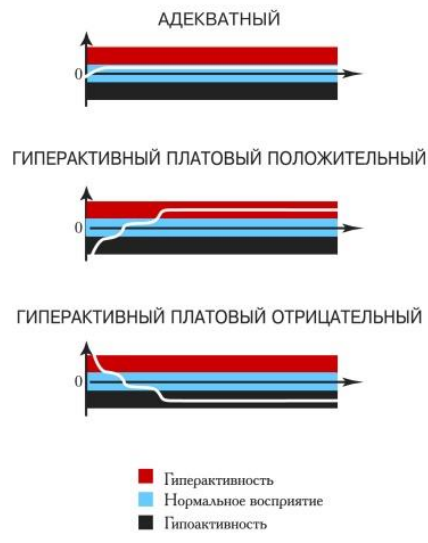


II. Гиперактивный пиковый: 1) позитивный; 2) негативный; 3) комбинирован-ный. 2. III. Парадоксальный. IV. Хаотичный. В каждом из типов определялся блокированный вариант - спонтанное или обусловленное прекращение эмоциональной реакции или её трансформация в противоположную.

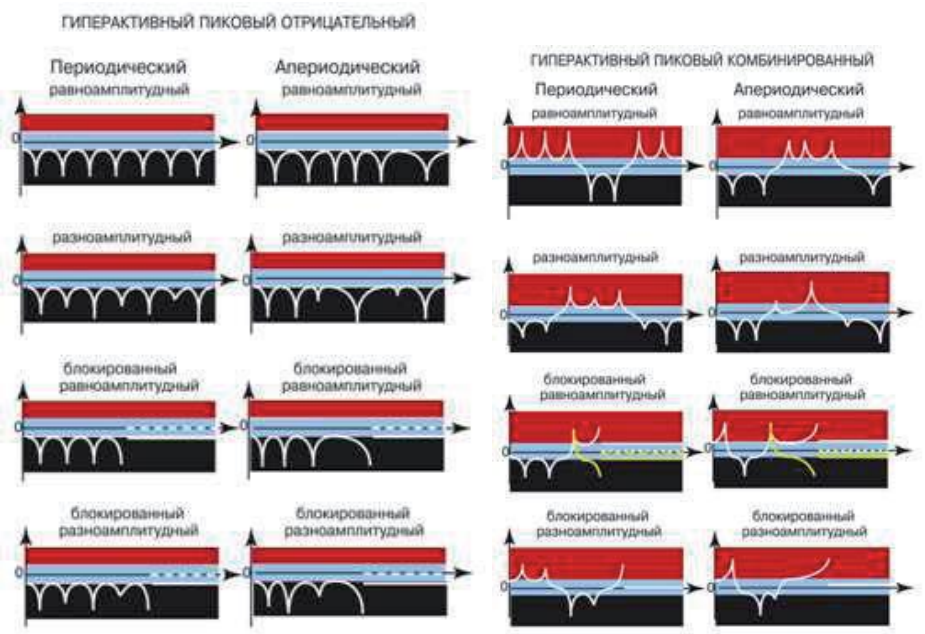

ГИЛЕРАКТИВНЫЙ пикОВЫЙ полОжИтЕЛЬНЫИ

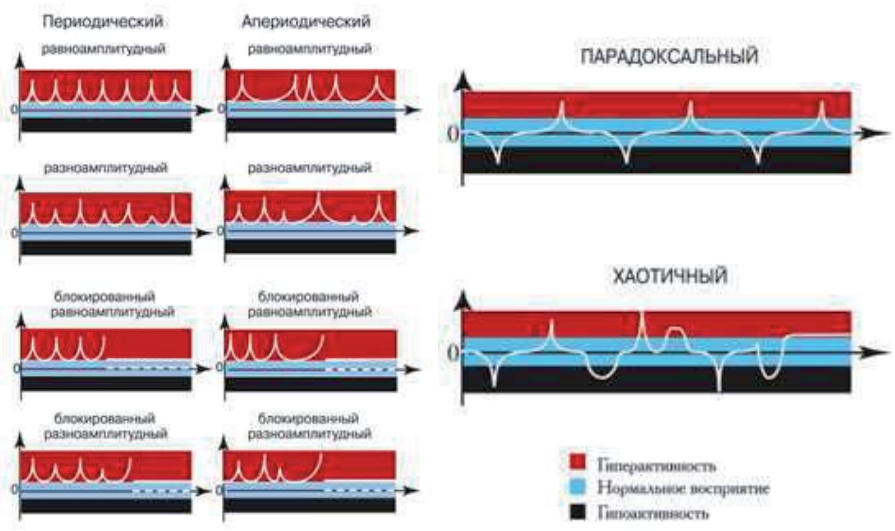

До коррекции для 83\% пациентов был характерен II тип, 12\% III тип, 5\% - IV тип, после коррекции: 75\% - I тип, 20\% -II тип, 5\% - III тип. 
Самооценка психоэмоционального состояния до коррекции: очень плохое $-18 \%$, плохое $-74 \%$, удовлетврительное $-8 \%$, после коррекции: плохое $-6 \%$, удовлетворительное $-24 \%$, хорошее $-57 \%$, отличное $13 \%$. Индексы психо-эмоционаьіного напряжения до и после коррекции соответственно : тревож-ность 8,7 - 2,2, агрессивность 4,7 - 1,3, страх смерти $8,7-2,2$, одиночество $5,8-2,3$, отчаяние $4,9-1,5$, суицидность 3,5 - 1,1, депрессия 9,6 - 2,4. Самооцен-ка состояния по ТЕСС: выбор квадрата с чёрним центром - $86-23 \% \%$, с белым центром $-9-77 \% \%$. После коррекции отмечалось улучшение кардио-гемодинамики: увеличились сердечный и ударный индексы, минутный объём кровообращения, уменьшилась фаза напряжения правого желудочка $(\mathrm{P}<.0,05)$. Систолическое артериальное давление снизилось с $173 \pm 1$ до $132 \pm 1$ мм рт. ст. $(\mathrm{P}<.0,05)$, диастолическое - с $104 \pm 1$ до $83 \pm 1$ мм рт. ст. $(\mathrm{P}<.0,05)$. Частота и длительность ишемических эпизодов уменьшились у 77\% пациен-тов. У $67 \%$ пациентов значительно уменьшены дозы $\beta$-адреноблокаторов и блокаторов кальциевых каналов при сохранении стабильных параметров кар-диогемодинамики. У 54\% пациентов отменены транквилизаторы.

ТЕСС и СУПН позволяют определять и контролировать уровень психоэмо-ционального напряжения и психологическую реактивность при ИБС, ГБ и СФР, а ЛОК и ГМ - значительно снижать его и продуктивно моделировать реактивность пациентов с улучшением их кардиогемодинамики.

\section{Литература:}

1. Сісецький А.П. Спосіб особистісної стабілізації пацієнта візуалізацією власного стану. Патент на корисну модель № 35151. 2008.

2. Harshfield E. L., Pennells L., Schwartz J. E. et al. Association Between Dep-ressive Symptoms and Incident Cardiovascular Diseases. JAMA. 2020; 324(23): 2396-2405.

3. Sisetskiy A. P. Holographic modeling in coronary artery disease, hypertension and anxiety-depressive disorders. «Медичні та фармащевтичні науки: Аналіз сучасності та прогноз майбутнього». 13-14.11. 2020. Збірник матеріалів міжнародної науково-практичної конферениії. Дніпро. 2020. С. 67-71. 